Questions de communication

$24 \mid 2013$

Renouvellement des mises en scène télévisuelles de la politique

\title{
Hervé GLEVAREC, La culture à l'ère de la diversité
}

La Tour d'Aigues, Éd. L'Aube, coll. Monde en cours, 2013, 112 pages

\section{Alexandre Eyries}

\section{(2) OpenEdition}

\section{Journals}

Édition électronique

URL : http://journals.openedition.org/questionsdecommunication/8764

DOI : 10.4000/questionsdecommunication.8764

ISSN : 2259-8901

\section{Éditeur}

Presses universitaires de Lorraine

Édition imprimée

Date de publication : 31 décembre 2013

Pagination : 255-257

ISBN : 978-2-8143-0182-5

ISSN : 1633-5961

\section{Référence électronique}

Alexandre Eyries, "Hervé GLEVAREC, La culture à l'ère de la diversité », Questions de communication [En

ligne], 24 | 2013, mis en ligne le 01 février 2014, consulté le 22 septembre 2020. URL : http:// journals.openedition.org/questionsdecommunication/8764 ; DOl : https://doi.org/10.4000/ questionsdecommunication.8764 
et « personnel/universel » dans leur appréhension des phénomènes socioculturels. Ainsi démontre-t-elle que ces auteurs sont à même de dépasser les limites que fixent la nationalité et les phénomènes culturels. À son tour, Fernando Andacht (pp. | 3 | - |53) pose la question de la représentation de l'identité culturelle, cette fois dans le cas de la musique populaire uruguayenne. En démontrant le réductionnisme propre à la dichotomie critique relative à la création musicale « locale/ étrangère », Fernando Andacht souligne que cette chanson populaire est vectrice d'une représentation «transculturelle » de l'identité uruguayenne. Quant à Zila. Bernd (pp. 155-163), elle offre un fabuleux panorama des cultral studies canadiennes au Brésil. Avant tout, ces dernières se veulent signe de la reconnaissance de l'altérité sans référence obligatoire aux canons culturels et théoriques européens, déconstruisent la dichotomie « centre/périphérie ». Ce qui, selon l'auteure, ouvre la voix à une nouvelle conception du « Nord » perçu dans sa dynamique «transaméricaine ». La contribution de Winfried Siemerling vient clore cette section examinant les perspectives binaires. Sa contribution intitulée « Mary Ann Shadd, la diaspora africaine et les Amériques » (pp. 165-177) est une réflexion sur une étude « multiculturaliste » de Mary Ann Shadd. Cette optique « transnationaliste » dans laquelle s'engage l'auteure la fait se confronter à d'autres questions terminologiques telles celles posées par les concepts de « cosmopolite », de « diaspora » ou encore de « postcolonial ». À bien des égards, sa réflexion permet de mettre à l'épreuve les usages et les limites de ces notions.

La troisième section de l'ouvrage porte le titre « Inclusions/exclusions » (pp. |8|-2|7). C'est au mécanisme du discours politique de l'Amérique latine que s'intéresse Isaac Nahon Serfaty (pp. 181-204) dans l'étude qui l'ouvre. L'auteur interroge le cas vénézuélien et étudie de manière très judicieuse la réintroduction des éléments mythiques dans ce discours, le rendant «néomythique » sur l'identité et l'appartenance nationale dans un contexte de modernité et de mondialisation, reconnaissant au mythe sa force constructive de sens. Maria Fernanda Arentsen (pp. 205-217) termine la section en analysant le concept d'« exclusion », en illustrant sa réflexion par l'exemple du handicap comme différence visible. Selon l'auteure, l'exclusion résulte d'une conception de l'humanité structurée par le rapport « dominant/dominé » et pose l'hypothèse selon laquelle seul un contexte « transculturel » peut éliminer la hiérarchie et sa logique exclusive.

La quatrième et dernière section porte le titre « Appartenances spécifiques et contexte global » (pp. 2I2-24I). N'y figure qu'une seule contribution, celle de Boulou Ebanda De B'béri. L'auteur réfléchit sur les films de Raoul Peck,Abderrahmane Sissako et Jean-Marie Téno dans une perspective dite « transgéographique ». \| souligne et analyse pertinemment les énoncés idéologiques que ces films véhiculent et constate que ces production cinématographiques sont des médiateurs permettant de véhiculer une mythologique « transgéographique » : celle de l'africanité. Ainsi cette conception « a-nationale » de l'« appartenance » rejette-t-elle l'idée des « identités nationales africaines » issue de la colonisation.

Ensemble de réflexions aussi originales les unes que les autres, I'ouvrage a le mérite de conceptualiser les termes de « trans 》, « multi » et « inter » tout en faisant éclater les frontières entre les disciplines et la culture, faisant ainsi converger science, société et esthétique dans une réorganisation alimentée directement par un contexte de mondialisation effaçant les contours usuels.

\section{Ammar Benkhodja \\ CREM, université de Lorraine, F-57000 a.benkhodja@gmail.com}

\section{Hervé Glevarec, La culture à l'ère de la diversité.}

La Tour d'Aigues, Éd. L'Aube, coll. Monde en cours, 2013, 112 p.

D'emblée, l'ouvrage présenté par Hervé Glevarec, directeur de recherche au Centre national de la recherche scientifique et chercheur au Laboratoire communication et politique, s'impose par son angle d'attaque et par la richesse de la problématique qui en structure les analyses. En effet, en tant que spécialiste reconnu de la sociologie de la culture et des médias, l'auteur choisit de réinterroger, 34 ans après, la postérité d'un livre publié en 1979 par Pierre Bourdieu (La Distinction. Critique sociale du jugement, Paris, Éd. de Minuit) et qui est toujours considéré comme l'acte fondateur d'une discipline qui en était encore à ses balbutiements : la sociologie de la culture.

Cependant, depuis, le développement et la diversification du champ des biens culturels ont provoqué un grand nombre de bouleversements dans la structuration et la signification même des goûts et des pratiques culturelles. La principale originalité de l'essai d'Hervé Glevarec provient de sa volonté de rendre compte le plus précisément possible des pratiques émergentes en matière de consommation culturelle afin d'en dessiner un état des lieux fidèle. Comme le rappelle l'auteur, les sociologues ont principalement vocation à rendre compte de la place de plus en plus prépondérante prise dans les pratiques des individus (et le plus souvent des 
catégories les plus diplômées), par des genres culturels « n'appartenant pas à la culture classique comme les musiques jazz, rock, électroniques, la littérature policière, la bande dessinée, les jeux vidéo, les séries télévisées, etc. mais aussi de la [...] baisse de [...] la fréquentation de l'opéra, de la musique classique, des émissions culturelles ou encore de la littérature » (pp. 7-8)

Ces deux évolutions ont été décrites par certains sociologues (par exemple, Richard Peterson, « Understanding Audience Segmentation: Fromeline and Mass to Omnivore and Univore », Poetics, 21, 1992 pp. 243-258), d'une part, en termes d'éclectisme et, d'autre part, en termes d'affaiblissement de la légitimité culturelle de la culture classique. Le concept d'éclectisme culturel permet de désigner la superposition « de genres culturels anciennement populaires aux portefeuilles de goûts classiques des catégories supérieures et diplômées tandis que la dévaluation de la culture classique a été mise au compte d'un plus faible rendement de l'affichage culturel » (p.8). Pour séduisante et opératoire qu'elle soit, cette théorie n'en demeure pas moins une tentative de concevoir une taxinomie destinée à classer les pratiques culturelles en fonction de variables. Néanmoins, l'apport de cette proposition théorique de Richard Peterson (ibid.) doit être soumis à une analyse critique des plus rigoureuses. En effet, dans son développement, le sociologue américain occulte certaines catégories socioprofessionnelles pourtant riches d'enseignements. II semble méconnaitre l'accroissement pourtant significatif des pratiques culturelles des jeunes générations (spécifiquement des femmes) et des catégories populaires. C'est ce réexamen critique que prend en charge Hervé Glevarec, montrant que, en matière de sociologie culturelle, « les biens culturels peuvent [...] changer sans qu'aux yeux de certains [ne] bouge le contenant, à savoir la structure - maintenue -, la légitimité - reconduite - et l'explication par la distinction - défendue » (p. |3).

Dans la première partie de l'ouvrage, intitulée « Reconduction et déni » (pp. 19-44), l'auteur montre la difficulté inhérente à toute tentative de cartographie des pratiques culturelles des Français et la récurrence (pour ne pas dire l'omniprésence) de certains lieux communs propres à la définition du rapport des individus à la culture. II souligne avec finesse que la culture populaire contemporaine se voit le plus souvent minorée, décrédibilisée, voire occultée tant par les institutions que par les chercheurs qui la prennent pour objet d'étude. Simultanément, la légitimité de la dite « haute culture » tend à s'affaiblir de plus en plus. II semble donc que « l'arbre de la légitimité classique vient occulter la forêt des éclectismes culturels des catégories supérieures » (p. 31). Cela signifie qu'il n'y a pas d'automaticité entre la catégorie socioprofessionnelle d'un individu et les choix qu'il opère dès lors qu'il doit regarder un film au cinéma ou une émission de télévision à son domicile, visionner un DVD ou assister à une représentation théâtrale.

Même si elles s'en défendent avec véhémence, les catégories socioprofessionnelles les plus élevées " ont regardé de façon massive les films "Titanic", "Les Visiteurs" et "Les Bronzés" » (p. 32). Cet état de fait paradoxal s'explique par le concept de réalisations culturelles « omnibus 》 qui sont consommées indifféremment par différentes catégories sociales. Ainsi le cinéma indépendant et/ou d'auteur - La Vie des autres (Henckel, 2006), Le Secret de Brokeback Mountain (Lee, 2005), etc. - n'est-il pas l'apanage des catégories supérieures, non plus que les blockbusters spectaculaires et pleins d'effets spéciaux - Star Wars (Lucas, 1977-2005), Le Seigneur des anneaux (Jackson, 200 I-2003), etc. - ne sont celui des classes populaires. La réalité est plus complexe et plus nuancée : « Les individus diplômés formulent des jugements d'indifférence et de tolérance bien plus prononcés que la condescendance ou la pratique feinte à propos des pratiques populaires contemporaines qu'ils ont ou n'ont pas » (p. 35). Hervé Glevarec ne se limite pas à une analyse sociologique superficielle des pratiques culturelles assimilant les amateurs d'opéra ou de théâtre à des personnes vaniteuses. II va beaucoup plus loin que le voile des apparences. Les dernières enquêtes (Olivier Donnat, Les pratiques culturelles des français à l'ère numérique. Enquête 2008, Paris, Éd. La Découverte/ministère de la Culture et de la Communication, 2009) sur les pratiques culturelles ont révélé une montée considérable des genres populaires contemporains et une baisse des genres classiques parmi les jeunes générations. Le sociologue de la culture consigne « la perte d'audience des genres de la musique classique, du théâtre et de l'opéra et le gain d'audience des genres de la visite au musée, de la fréquentation du cinéma, des concerts de musique rock et, enfin, l'apparition de l'ordinateur dans les pratiques » (p. 37).

Dans la deuxième partie de l'ouvrage (« Diversité culturelle », pp. 45-62), l'auteur rappelle que l'évolution des pratiques culturelles a été accompagnée par l'extension et la diversification du champ culturel à partir des années 60 qui ont vu le déploiement des dispositifs médiatiques et des supports matériels de la culture de masse. L'offre culturelle institutionnelle s'est aussi diversifiée par l'intermédiaire des décisions étatiques et territoriales qui, ensuite, ont entamé un 
processus de « légitimation par les politiques culturelles des pratiques infraculturelles (rock, bande dessinée) mais aussi des goûts d'avant-garde » (p. 5I). L'extension considérable du nombre des genres culturels et du volume des œuvres est allée de pair avec une meilleure accessibilité des publics aux biens culturels de masse par les moyens techniques. En conséquence, les formes de la consommation culturelle « ont [...] évolué dans le sens de pratiques moins conventionnelles, plus ludiques, festives, participatives » (p.55). La transmission de la culture passe par un double mouvement de dissociation : d'une part, des scènes institutionnelles comme l'école ou le marché du travail et, d'autre part, des scènes sociales ordinaires de la sociabilité, celles des pairs. On explique ce mouvement de dissociation par une dialectique entre une culture de l'affichage et de la scène publique et entre une scène intime des goûts et des écoutes réelles plus éclectiques.

Dans la quatrième partie (« Faiblesses légitimistes », pp. 81-94), l'auteur pose la question de la légitimité des cultures contemporaines et prend l'exemple du rock : « l'assignation du rock à la catégorie des genres à moyenne légitimité culturelle [méconnaît] que le rock est dorénavant légitime parce que écouté par des catégories diplômées [... . et institutionnalisé aux yeux de certains » (p. 83). En conclusion, Hervé Glevarec (p. 95) souligne « l'hétérogénéité qu'il y a entre la culture et le savoir, entre le fait d'être cultivé et le fait de produire du savoir $\gg$. Cette analyse, éclairante à plus d'un titre pour le chercheur en sciences humaines et sociales, ouvre des perspectives nouvelles.

\section{Alexandre Eyries \\ 13M, université Nice Sophia Antipolis, F-06200 alex.eyries@yahoo.fr}

\section{Françoise Ménand Doumazane, Miroirs d'Aline. Ethnocritique d'un roman de C.F. Ramuz.}

Nancy, PUN-Éd. universitaires de Lorraine, coll. Ethnocritiques, 2013,349 p.

On s'est longtemps habitué à lire Aline, premier roman de Charles-Ferdinand Ramuz (Lausanne, Payot, 1905) comme la tragédie d'un personnage victime d'un innocent amour passionnel. Mais, à la lecture pluridisciplinaire, au carrefour des sciences des textes littéraires et de l'ethnologie du symbolique qu'en propose Françoise Ménand Doumazane, on apprendra vite que l'enjeu esthétique et poétique dépasse le cadre réaliste d'un drame amoureux. En effet, la chercheuse en révèle l'agora et l'architecture des voix culturelles qui s'y jouent et s'y orchestrent.
Cette professeure agrégée de lettres classiques et docteure en langue et littérature françaises explore donc l'esthétique et la poétique de Charles-Ferdinand Ramuz. Rencontrant l'esthétique picturale de Lorenzo Lotto dès la première scène du roman d'Aline, cette poétique se révèle petit à petit au long de ce parcours analytique qu'on a tant plaisir à lire grâce à un jeu de miroirs qui renvoie aux expériences sociales et scripturales de l'auteur tout en les faisant s'entrecroiser. Miroirs d'Aline s'ouvre sur une première partie intitulée «Aline en miroir » (pp. 2 | - | |4). Dans ses huit chapitres, la critique tente un parcourt « ethnobiographique », explorant les « commencements 》 de l'auteur. Ses 27 premières années sont parcourues : sa naissance et son enfance, son parcours à l'école préparatoire et ses années de collège jusqu'au moment où il commence l'expérience scripturale d'Aline. De cet ensemble d'« expériences », la chercheuse sélectionne des biographèmes dont elle propose une lecture cultuelle qui fait ressortir trois mots clés : 《 circulations 》, « passages 》 et « transactions 》. Ainsi l'ethnocritique éloigne-t-elle son approche des lectures biographiques classiques tout en mettant « en miroir

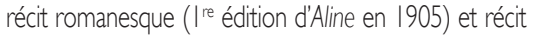

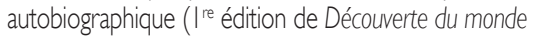
en 1993) » (p. 22). Conformément à la démarche ethnocritique, elle permet aussi de conjoindre littérature et sciences humaines. Françoise Ménand Doumazane relève aussi tous les croisements qui existent entre le texte de Charles-Ferdinand Ramuz et d'autres auteurs, tels François-René de Chateaubriand, John Berger...

La deuxième partie, « Aline au miroir 》 (pp. I 19-225), fait structurellement écho à celle qui la précède : elle est pareillement composée de huit chapitres. Ici, le miroir est orienté vers le matériau textuel qui se révèle être riche en éléments culturels. Données culturelles et symboliques que « Ramuz, par un travail d'écriture en spirale, s'approprie, réélabore et se réapproprie »(p. |19). Ainsi, s'agissant avant tout d'une étude tournée vers la littérarité du texte, l'auteure commence-t-elle par en étudier les grandes catégories narratives : espaces-temps, parcours actantiels des personnages et structure de l'intrigue y sont judicieusement décortiqués et, par la prouesse méthodologique que permet l'ethnocritique de la littérature, la chercheuse met au jour la polyphonie culturelle en œuvre. Catégorisant et nommant la configuration spatiale du roman grâce à des concepts empruntés à l'anthropologie, Françoise Ménand Doumazane a mis au point une structure ternaire lui permettant d'approcher anthropologiquement la réélaboration fictive de l'espace : la domus (espace 